\title{
The Use of Sorbents for the Removal of Selected Anions from Wastewater after Production of Soda Ash
}

\author{
Adam Gołub $^{1 *}$, Janina Piekutin ${ }^{1}$ \\ 1 Bialystok University of Technology, Department of Technology in Engineering and Environmental Protection, \\ Wiejska 45A, 15-351 Białystok, Poland \\ * Corresponding author's e-mail: a.golub@doktoranci.pb.edu.pl
}

\begin{abstract}
The research on the use of sorbents to remove anions from the wastewater after soda production was conducted due to the need to protect waters against the pollution at the source of its formation. In the case of industrial plants introducing wastewater to surface waters, this requires modification of the production line or an additional stage of wastewater treatment, which will prevent pollution of the environment. The wastewater generated in the Solvay soda ash production process is characterized by strong alkaline $\mathrm{pH}$, high electrolytic conductivity and high concentrations of chlorides, ammonia, sulfates, phosphates, calcium, potassium, sodium and magnesium. The paper presents the results of the research aimed at removing the chloride, sulfate and phosphate anions from wastewater from calcinated soda production using three sorbents: Halosorb, Compakt and Damsorb K. The ion removal process was carried out using a dynamic method with a varying deposit load in the range from $0.579 \mathrm{~m}^{3} /\left(\mathrm{m}^{2} \mathrm{~h}\right)$ to $1.937 \mathrm{~m}^{3} /\left(\mathrm{m}^{2} \mathrm{~h}\right)$. The concentrations of all tested anions were reduced, which indicates a high potential of the method and possibility of further, more detailed studies.
\end{abstract}

Keywords: sorbents, chlorides, sulfates, phosphates, soda ash, wastewater treatment

\section{INTRODUCTION}

The Water Framework Directive forces the EU Member States to protect the water resources from the pollution at its source [7]. In the case of industrial plants, it is necessary to modify the production processes in such a way that they generate as little wastewater as possible, which will have a minimal impact on the condition of the receiver or the introduction of an additional stage of wastewater treatment that will reduce or eliminate the environmental pollution.

The plants dealing in the production of light and heavy soda ash, belonging to chemical industry, are an example of a strong impact on natural waters. The production processes of modern plants are based on the Solvay method, which is associated with the formation of saline waste $[12$, $14,16]$. In the world, the method of managing the waste from soda plants, which would allow for the complete elimination of ecological damage, has still not been worked out. The wastewater treatment methods result mainly from local solutions. In Japan, China and India, the post-production waste was partly managed by producing $\mathrm{NH}_{4} \mathrm{Cl}$ used for the rice cultivation. The use of ammonium chloride in Europe would cause acidification of soils; therefore, this solution is excluded [10]. Mostly, agricultural lime is obtained from the waste. The remaining wastewater is directed to the surface waters, while the sludge is collected in the settlers $[4,5]$. In a situation where wastewater reaches rivers, the salinity of a receiver may be limited by adjusting the amount of waste discharged to the river states. It can be periodically collected in tanks and emptied at high water levels. Some plants additionally introduce a wastewater neutralization stage by mixing the strongly alkaline wastewater from the production of soda with the acidic wastewater obtained from other production. Other research concerns modification of the production technology and replacement 
of ammonia with primary and tertiary amines at the absorption stage [6]. Despite the satisfactory results at the pilot stage of the project, solutions have never been introduced on an industrial scale due to the risk of environmental pollution by amines and organic solvents. Another solution proposed in the literature is the recovery of calcium carbonate from the post-production wastewater using sodium carbonate that does not meet the quality requirements of sodium [9]. However, it is a method, in which the precipitating accompanying salts, such as magnesium carbonate, pollute the final product and thus makes it useless.

The soda producing plants minimize their negative impact on the natural environment by pre-treating the post-production wastewater and preventing from their contact with the underground and surface waters. At the same time, they are trying to implement innovative solutions that reduce the costs associated with environmental protection. For this reason, the interest in the socalled "low-cost" materials or, more broadly, the methods that are both effective and economical, is observed in the field of the research [8]. One of the "low-cost" methods that deserves special attention is the use of porous materials, i.e. sorbents, that are readily-available, easily applicable, cheap and, which is important, non-toxic to the environment.

The aim of the research presented in this paper was to remove the selected anions from the wastewater after production of soda ash during the sorption process.

\section{METHODS}

Three sorbents were used for the tests: Halosorb (processed halloysite), Compakt and
Damsorb K (both are diatomaceous calcined earth). Physical and chemical properties of the materials used are shown in Table 1.

The wastewater generated in the production process of soda ash is a mixed liquid waste from two production plants: Soda Mątwy in Inowrocław and Janikosoda in Janikowo. They are characterized by strongly alkaline $\mathrm{pH}$, high electrolytic conductivity and high concentration of chlorides, ammonia, sulfates, phosphates, calcium, potassium, sodium and magnesium. The tests determined the concentrations of three anions: chloride, sulfate and phosphate. The whole cycle of tests was carried out using actual wastewater.

\section{Methodology of technological and analytical research}

The anion removal process was carried out by means of dynamic method in three columns, each filled with another sorbent weighing $250 \mathrm{~g}$. Before the basic study, the deposits were rinsed with distilled water. Wastewater with a volume of $500 \mathrm{~cm}^{3}$ was filtered through the test material. At the end of the process, $250 \mathrm{~cm}^{3}$ of test samples were taken for determinations. Four series of tests were carried out. In each of them, different load of deposit was applied (Table 2). After the experiment, the sorbent columns were again rinsed with distilled water. The described research was carried out twice.

Determinations of chloride concentration in individual series were made with the Mohr titration method, whereas sulfates and phosphates applying the Hach spectrophotometric method.

The results of the study were statistically analyzed using the Statistica 13 package. The following tests were used during the

Table 1. Physicochemical properties of sorbents used for testing

\begin{tabular}{|l|c|c|c|}
\hline \multicolumn{1}{|c|}{ Parameter } & Halosorb & Compakt & Damsorb K \\
\hline Grain diameter [mm] & $0.2-3$ & $0.3-0.7$ & $0.3-1.5$ \\
\hline Average loose density $\left[\mathrm{g} / \mathrm{dm}^{3}\right]$ & 680 & 525 & 429 \\
\hline & $-\mathrm{SiO}_{2}(40 \%)$ & $-\mathrm{SiO}_{2}(75 \%)$ & $-\mathrm{SiO}_{2}(71 \%)$ \\
& $-\mathrm{Al}_{2} \mathrm{O}_{3}(33 \%)$ & $-\mathrm{Al}_{2} \mathrm{O}_{3}(10 \%)$ & $-\mathrm{Al}_{2} \mathrm{O}_{3}(10.5 \%)$ \\
& $-\mathrm{Fe}_{2} \mathrm{O}_{3} / \mathrm{FeO}(8 \%)$ & $-\mathrm{Fe}_{2} \mathrm{O}_{3}(7 \%)$ & $-\mathrm{Fe}_{2} \mathrm{O}_{3}(8.4 \%)$ \\
& $-\mathrm{TiO}_{2}(2 \%)$ & $-\mathrm{MgO}^{2}(2 \%)$ & $-\mathrm{CaO}^{2}(2.5 \%)$ \\
Chemical composition & $-\mathrm{CaO}(1.3 \%)$ & $-\mathrm{TiO}_{2}(1 \%)$ & $-\mathrm{K}_{2} \mathrm{O}+\mathrm{Na}_{2} \mathrm{O}(2.1 \%)$ \\
& $-\mathrm{MgO}_{2}(0.5 \%)$ & $-\mathrm{CaO}(1 \%)$ & $-\mathrm{MgO}^{2}(1.6 \%)$ \\
& $-\mathrm{Na}_{2} \mathrm{O}(0.1 \%)$ & $-\mathrm{K}_{2} \mathrm{O}+\mathrm{Na}_{2} \mathrm{O}(2 \%)$ & $-\mathrm{TiO}_{2}(1.4 \%)$ \\
\hline pH (10\% water suspension) & $-\mathrm{K}_{2} \mathrm{O}(0.1 \%)$ & 5.5 & 5.5 \\
\hline Absorptivity [\%] & 7.0 & $90-110$ & $90-130$ \\
\hline
\end{tabular}


Table 2. Deposit loads in subsequent series of tests

\begin{tabular}{|c|c|}
\hline Test series & Deposit load $\left[\mathrm{m}^{3} /\left(\mathrm{m}^{2} \mathrm{~h}\right)\right]$ \\
\hline 1. & 1.937 \\
\hline 2. & 1.628 \\
\hline 3. & 0.969 \\
\hline 4. & 0.579 \\
\hline
\end{tabular}

analysis: Shapiro-Wilk, two-factor analysis of variance (ANOVA of main effects), Scheffé and Kruskal-Wallis.

\section{RESULTS AND DISCUSSION}

\section{Chlorides}

The degree of chloride ions removal in the sorption process (Figure 1) is presented as the average result, also indicating the standard deviation. The removal of chlorides by Halosorb ranged from $10.13 \%$ to $30.38 \%$, Compakt - from $12.69 \%$ to $64.82 \%$, and by Damsorb K - from $27.59 \%$ to $49.37 \%$. The obtained values of the ion concentration decrease differed with subsequent loads of the deposit. The effectiveness of sorption for all sorbents was the lowest in the first series of tests, it grew in II and reached maximum values in the third series (the highest was obtained for Compakt $-65 \%$ ). In the fourth series, the degree of removal decreased. It could be caused by blocking of sorbent pores by suspension particles present in the wastewater during the slow flow through the column. This was not the case during the fast flow when these molecules were washed away by the filtered liquid.
For comparison, scientific reports quoted that the chloride ion concentration was reduced by about 10-30\% using nanofiltration [2] and even $99 \%$ using reverse osmosis [15]. Evaporation allows for the removal of about $80-90 \%$ chlorides from water [13]. The use of a precipitation process, e.g. with amine solvents such as isopropylamine, is not effective - the result was close to $0 \%$ [3]. Compared to nanofiltration or the use of amine solvents, sorbents give satisfactory chloride removal effect; however, reverse osmosis or evaporation allows for a much better result.

In order to investigate the significance of differences between the results obtained for various sorbents and the loads of deposit, appropriate statistical tests were applied. The Shapiro-Wilk test was used to verify normality of the variables distribution. At the significance level $\alpha=0.05$, the probability level $p=0.06414$ was determined. The probability level $p$ has a value higher than the significance level $\alpha$, thus there is no reason to reject the null hypothesis about the normality of distribution. Therefore, a two-factor analysis of variance (ANOVA of main effects) was selected to assess the impact of two factors: type of sorbent and load on the amount of chloride removal from wastewater, assuming two null hypotheses:

- Type of sorbent does not differentiate the results of the experiment.

- Deposit load does not differentiate the results of the experiment.

After the analysis, it was found that with the probability level $p=0.001637$, the hypothesis about the lack of influence of sorbent type on the process efficiency should be rejected. With the probability level $p=0.000948$, the hypothesis

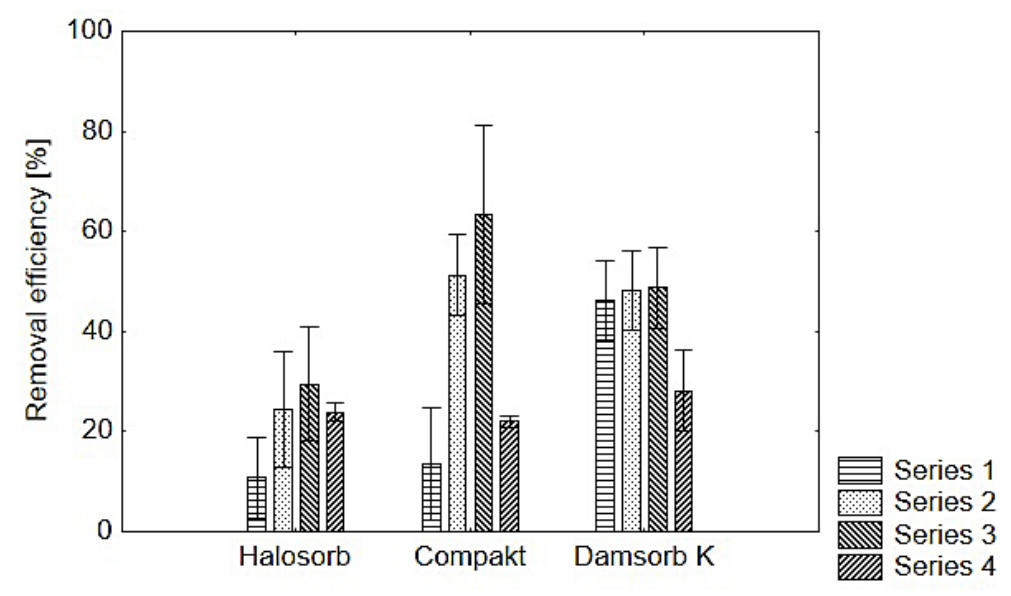

Figure 1. Average degree of removal of chloride ions and its standard deviation in the sorption process on tested materials: Halosorb, Compakt and Damsorb K 


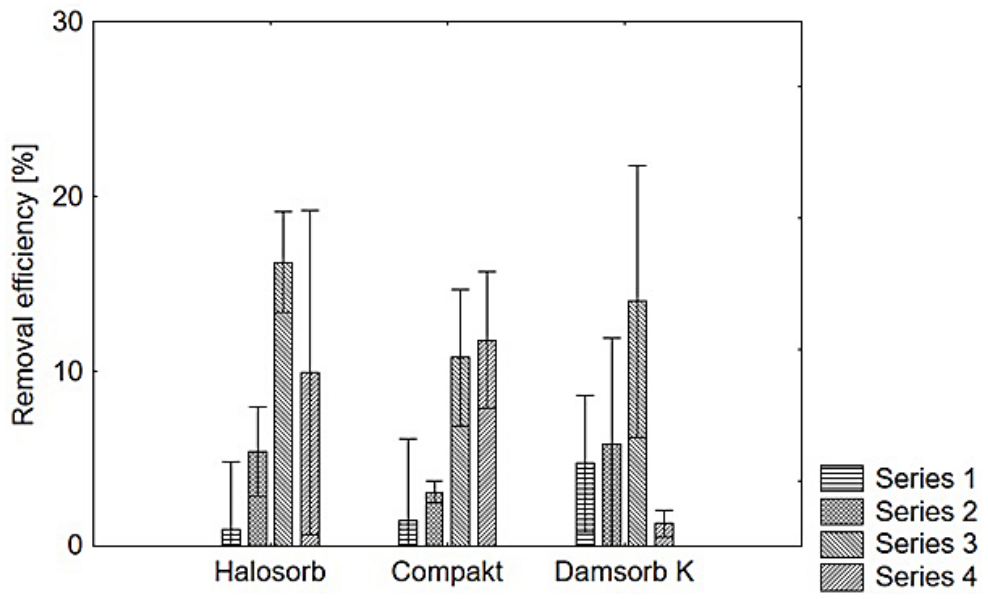

Figure 2. Average degree of sulfate ions removal and its standard deviation in the sorption process on tested materials: Halosorb, Compakt and Damsorb K

about the absence of a deposit load impact should also be rejected. Therefore, the analysis of variance shows that both these factors have a significant impact on the degree of chloride reduction.

In order to determine which of the compared sorbents significantly differ in the effectiveness of removing chloride ions, the Scheffé post-hoc test was additionally carried out (Table 3 ). Two homogeneous groups were created. The first group included Damsorb K and Compakt, which showed the highest efficiency $(38 \%-43 \%)$, and the second group - Halosorb that reduced the concentration of chlorides at a lower level $(22 \%)$.

The Scheffé test was then carried out to determine the most effective deposit load for each

Table 3. Scheffé test results for average chloride ions removal rates by the sorbents tested

\begin{tabular}{|c|c|c|c|}
\hline Sorbent & $\begin{array}{c}\text { Average chlorides } \\
\text { removal efficiency [\%] }\end{array}$ & 1 & 2 \\
\hline Halosorb & 22.15 & & ${ }^{* * *}$ \\
\hline Compakt & 37.56 & ${ }^{* * *}$ & \\
\hline Damsorb K & 42.85 & ${ }^{* * *}$ & \\
\hline
\end{tabular}

sorbent (Table 4). Halosorb revealed the best result in the III series of tests $(29 \%)$, slightly worse in the II and IV series (24\%), and by far the worst in the I series (11\%). The effectiveness of Compakt was also the highest in the III series of tests $(63 \%)$, it decreased in the II series $(51 \%)$, while in the series IV and I, it was the lowest $(14 \%-22 \%)$. The least diversified results were obtained for Damsorb K, for which in the III, II and I series, the results were almost equally high $(46 \%-49 \%)$, while in the IV series - significantly lower (28\%).

\section{Sulfates}

The sulfate ions removal degree during the sorption process (Figure 2) is presented as the average result with standard deviation. The removal of sulfates by Halosorb ranged from $0.61 \%$ to $16.44 \%$, Compakt from $1.1 \%$ to $12.09 \%$, and Damsorb K from $0.12 \%$ to $14.6 \%$. The obtained values of ion concentration reduction were different for subsequent loads of the deposit. Similarly as in the case of chlorides, when the deposit was

Table 4. Scheffé test results for average chloride ions removal rates in successive measurement series with sorbent type as a grouping factor

\begin{tabular}{|c|c|c|c|c|c|c|c|c|c|c|c|c|c|c|}
\hline \multicolumn{5}{|c|}{ Halosorb } & \multicolumn{6}{|c|}{ Compakt } & \multicolumn{4}{|c|}{ Damsorb K } \\
\hline Series & $\begin{array}{c}\text { Average } \\
\text { chloride } \\
\text { removal } \\
\text { efficiency } \\
{[\%]}\end{array}$ & 1 & 2 & 3 & Series & $\begin{array}{c}\text { Average } \\
\text { chloride } \\
\text { removal } \\
\text { efficiency } \\
{[\%]} \\
\end{array}$ & 1 & 2 & 3 & 4 & Series & $\begin{array}{c}\text { Average } \\
\text { chloride } \\
\text { removal } \\
\text { efficiency } \\
{[\%]}\end{array}$ & 1 & 2 \\
\hline 1 & 10.75 & & $* * *$ & & 1 & 13.57 & *** & & & & 4 & 28.22 & & $* * *$ \\
\hline 4 & 23.93 & $* * *$ & & & 4 & 21.96 & & $\star \star * *$ & & & 1 & 46.20 & $* * *$ & \\
\hline 2 & 24.41 & $* * *$ & & & 2 & 51.26 & & & $\star * *$ & & 2 & 48.22 & $* * *$ & \\
\hline 3 & 29.48 & & & $\star * * *$ & 3 & 63.42 & & & & $* * *$ & 3 & 48.73 & $* * *$ & \\
\hline
\end{tabular}


heavily loaded in the first series of tests, the efficiency achieved by sorbents was low and increased with the decrease of the deposit load in series II and III (Halosorb achieved the best result in the third series of tests $-16 \%$ ). Moreover, during the removal of sulfates, there was a decrease in the efficiency in the fourth series of studies for Halosorb and Damsorb. The causes of this phenomenon may be similar to those of chlorides. The decrease did not occur in the removal of sulfates on the Compakt and in the fourth series, the obtained result was the highest for this sorbent.

The studies carried out by other authors revealed that the concentration of sulfate ions was reduced by over $99 \%$ using both nanofiltration and reverse osmosis [2, 15]. The evaporation method was able to reduce the sulfate concentration by almost $40 \%$ [13]. The use of precipitation with amine solvents, such as isopropylamine, allowed to reduce the sulfate concentration by about 50-60\% [3]. Against the background of the aforementioned methods, the use of sorbents for removing sulfates in the form presented in the study was ineffective. However, there is a chance that the modification of their surface could significantly increase the efficiency.

While checking the normality of the variables distribution, the Shapiro-Wilk test was applied again. Assuming the significance level $\alpha=0.05$, the probability level was determined as $p=0.01393$. Due to lower value of the probability level $p$ than the significance level $\alpha$, the null hypothesis about normality of the distribution had to be rejected. The Kruskal-Wallis test was used to assess the influence of two factors: type of sorbent and deposit load on the degree of sulfate removal from wastewater, assuming two null hypotheses:

- Type of sorbent does not differentiate the results of the experiment.

- Deposit load does not differentiate the results of the experiment.
The test enabled to conclude that with the probability level $p=0.637$, there is no reason to reject the hypothesis about the lack of influence of the sorbent type on the efficiency of the process. At the probability level $p=0.0032$, however, the hypothesis about the absence of a deposit load impact should be rejected. On the basis of the analysis of variance, it was found that only the load on the deposit has a significant impact on the degree of sulfate ions removal from wastewater.

In order to select the most effective deposit loading for each sorbent, the Scheffé post-hoc test was carried out (Table 5). On this basis, the highest efficiency of Halosorb in the III series of tests was determined $(16 \%)$, which significantly differed from other series, where in II series, it was $10 \%$, in IV $-5 \%$, while in I - only $1 \%$. In the case of Compakt, the best removal effect was observed in the III and the II series of tests (11-12\%), while in the IV and I series, it was much smaller (1-3\%). Damsorb K removed the sulfates to the highest degree in the III series (14\%), whereas in the remaining series, the level of reduction was much lower (1-5\%).

\section{Phosphates}

The degree of phosphate ions removal in the sorption process (Figure 3 ) is presented as the average result, also indicating the standard deviation. The phosphates on Halosorb were removed in the range from $0.2 \%$ to $4.41 \%$, on Compakt - from $32.31 \%$ to $52.22 \%$, while on Damsorb K from $2.78 \%$ to $20.37 \%$. The values of ion concentration decrease differed for subsequent loads of the deposit. The Halosorb efficiency in phosphate removal was very low, close to $0 \%$, regardless of the deposit load applied. Compakt gave much better effect, especially in the third series of tests, achieving over $52 \%$ removal. Low efficiency was demonstrated by Damsorb K, mainly in the third

Table 5. Scheffé test results for average sulfate ions removal rates in successive measurement series with sorbent type as a grouping factor

\begin{tabular}{|c|c|c|c|c|c|c|c|c|c|c|c|c|c|c|}
\hline \multicolumn{6}{|c|}{ Halosorb } & \multicolumn{4}{|c|}{ Compakt } & \multicolumn{5}{|c|}{ Damsorb K } \\
\hline Series & $\begin{array}{c}\text { Average } \\
\text { sulfate } \\
\text { removal } \\
\text { efficiency } \\
{[\%]}\end{array}$ & 1 & 2 & 3 & 4 & Series & $\begin{array}{c}\text { Average } \\
\text { sulfate } \\
\text { removal } \\
\text { efficiency } \\
{[\%]}\end{array}$ & 1 & 2 & Series & $\begin{array}{l}\text { Average } \\
\text { sulfate } \\
\text { removal } \\
\text { efficiency } \\
{[\%]}\end{array}$ & 1 & 2 & 3 \\
\hline 1 & 0.92 & $* * *$ & & & & 1 & 1.47 & $* * *$ & & 4 & 0.98 & $* * *$ & & \\
\hline 4 & 5.41 & & $* * *$ & & & 4 & 3.10 & $* * *$ & & 1 & 1.29 & $* * *$ & $* * *$ & \\
\hline 2 & 9.92 & & & $* * *$ & & 2 & 10.79 & & $* * *$ & 2 & 4.73 & & $* * *$ & \\
\hline 3 & 16.21 & & & & $* * *$ & 3 & 11.77 & & $* * *$ & 3 & 13.98 & & & *** \\
\hline
\end{tabular}




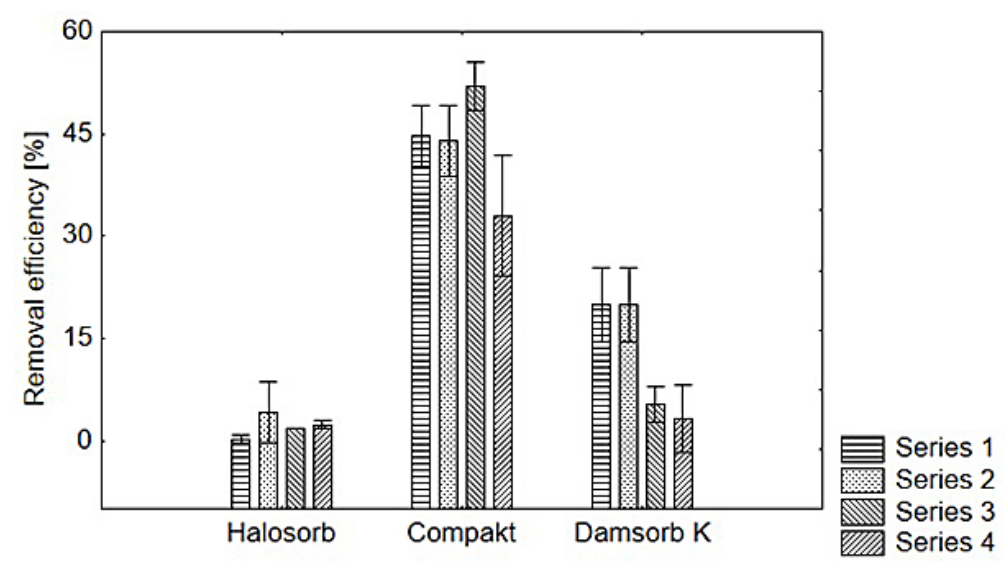

Figure 3. Average degree of removal of phosphate ions and its standard deviation in the sorption process on tested materials: Halosorb, Compakt and Damsorb K

and fourth series of tests, where it reduced the concentration of phosphates to a minimum (less than $6 \%$ ). There was a noticeable decrease in the effectiveness of the process in the fourth series of tests, which confirms the assumptions related to the blocking of sorbent pores at low deposit loads, described in point 3.1.

A much better effect of removing phosphates from water was obtained by other researchers, who used the Phoslock sorbent for the process. Reduction in the concentration of phosphate ions reached up to $85 \%$ [18]. The use of the coagulation process gave the effect of up to $80 \%$ removal [1]. The use of electrocoagulation for this purpose combined with the flocculation of the cationic polymer removed phosphates up to $97 \%$ [17]. In this view, only the Compakt sorbent, subject to the modification of its sorption surface, gives the potential to achieve high efficiency in the removal of phosphates.

Verifying the normality of the variables distribution required the use of the Shapiro-Wilk test. The level of probability defined at the significance level of $\alpha=0.05$ was $p=0.00077$, which suggests rejecting the hypothesis about distribution normality $(p<\alpha)$. The Kruskal-Wallis test was used to investigate the influence of sorbent type and deposit load. The adopted two null hypotheses were as follows:

- Type of sorbent does not differentiate the results of the experiment.

- Deposit load does not differentiate the results of the experiment.

After analyzing the test results, it was found that with the probability level $p=0.0001$, the hypothesis that the type of sorbent does not influence the efficiency of the process should be rejected. However, at the probability level $p=0.7446$, one should accept the hypothesis that there is no impact of the load on the deposit. Thus, it was concluded that only the type of sorbent has a significant effect on the removal of phosphate ions from wastewater.

Selection of the most effective sorbent required the use of the Scheffé test, the results of which are presented in Table 6. Statistically significant differences were observed between the levels of phosphate removal by all materials. The highest efficiency was demonstrated by Compakt (43\%), while Damsorb K and Halosorb were significantly less effective (2-12\%).

Table 6. Scheffé test results for average phosphate ions removal rates by the sorbents tested

\begin{tabular}{|c|c|c|c|c|}
\hline Sorbent & $\begin{array}{c}\text { Average phosphates } \\
\text { removal efficiency [\%] }\end{array}$ & 1 & 2 & 3 \\
\hline Halosorb & 2.13 & $* * *$ & & \\
\hline Damsorb K & 12.1 & & $* * *$ & \\
\hline Compakt & 43.45 & & & $* * *$ \\
\hline
\end{tabular}

\section{CONCLUSIONS}

Sulfates and phosphates are found in wastewater at lower concentrations than chlorides, but their removal is necessary to improve the water quality. Both of these ions are removed by sorbents to a lesser extent than chloride ion. Sulfates were maximally reduced by $16 \%$ by Halosorb at the flow through the column equal to $0.969 \mathrm{~m}^{3} /\left(\mathrm{m}^{2} \mathrm{~h}\right)$. In the case of phosphates, Compakt achieved the best effect from among tested materials (over $50 \%$ at the deposit load of $0.969 \mathrm{~m}^{3} /\left(\mathrm{m}^{2} \mathrm{~h}\right)$ ). 
During the tests, a significant decrease in efficiency in the fourth series was observed, when the load on the deposit was the lowest, amounting to $0.579 \mathrm{~m}^{3} /\left(\mathrm{m}^{2} \mathrm{~h}\right)$. The probable cause of this phenomenon is blocking of sorbent pores during slow flow through the column by suspension particles present in the wastewater. During the fast flow, suspended particles are washed away by the flowing wastewater and this effect does not take place.

The following conclusions were drawn from the conducted research:

- Compakt and Damsorb K were the most effective sorbents in the chloride removal.

- Phosphate removal was most effective with the use of Compakt sorbent.

- A significant effect of the deposit load on the degree of chlorides and sulfates removal has been demonstrated.

- Insufficient load on the deposit may lead to a decrease in sorption efficiency.

\section{Acknowledgements}

The research was carried out as part of the work MB/WBiIS/13/2019 and statutory work S/ WBiIŚ/3/2014 and funded by the Ministry of Science and Higher Education.

\section{REFERENCES}

1. Arnaldos M., Pagilla K. 2010. Effluent dissolved organic nitrogen and dissolved phosphorus removal by enhanced coagulation and microfiltration. Water Research, 44, 5306-5315.

2. Bader M.S.H. 2008. Analysis of the Paradox Valley brine desulfation by nanofiltration. Desalination, 229, 33-51.

3. Bader M.S.H. 2008. Innovative processes to desulfate the Paradox Valley brine. Desalination 229, 52-67.

4. Decision of the Marshal of the Kuyavian-Pomeranian Voivodship in Toruń no. ŚG-IV.7222.15.2015. AMK (26.02.2016). [in Polish]

5. Decision of the Marshal of the Kuyavian-Pomeranian Voivodship in Toruń no. ŚG-IV.7222.14.2015. AMK (18.09.2016). [in Polish]

6. Dittmeyer R., Keim W., Kreysa G., Oberholz A. 2005. Chemical Engineering. Processing and products, volume 3: Inorganic Basic Materials, Intermediates. Weinheim: Wiley VCH. [in German]

7. European Commission. 2000. Directive 2000/60/ EC of the European Parliament and of the Council of 23 October 2000 establishing a framework for community action in the field of water policy. Official Journal of the European Union, 2000.

8. Kamiński W., Tomczak E. 2014. Low-cost sorbents application for water treatment. Proceedings of ECOpole, 8(1), 189-194. [in Polish]

9. Kasikowski T., Buczkowski R., Lemanowska E. 2004. Cleaner production in the ammonia-soda industry: an ecological and economic study. Journal of Environmental Management, 73, 339-356.

10. Kicińska A., Gucwa J., Kosa-Burda B. 2019. Evaluating Potential for Using Municipal Sewage Sludge in the Rehabilitation of Ground Degraded by the Sodium Processing Industry. Bulletin of Environmental Contamination and Toxicology, 102(3), 399-406.

11. Loganathan P., Vigneswaran S., Kandasamy J., Bolan N.S. 2013. Removal and recovery of phosphate from water using sorption. Critical Reviews in Environmental Science and Technology, 44(8), 847-907.

12. Matthews D.A., Effler S.W. 2003. Decreases in pollutant from residual soda ash production waste. Water, Air, \& Soil Pollution, 146, 55-73.

13. Mohammadesmaeili F., Badr M., Abbaszadegan M., Fox P. 2010. Mineral recovery from inland reverse osmosis concentrate using isothermal evaporation. Water Research, 44, 6021-6030.

14. Şener S. 2008. Use of solid wastes of the soda ash plant as an adsorbent for the removal of anionic dyes: Equilibrium and kinetic studies. Chemical Engineering Journal, 138, 207-214.

15. Shaffer D.L., YinYip N., Gilron J., Elimelech M. 2012. Seawater desalination for agriculture by integrated forward and reverse osmosis: Improved product water quality for potentially less energy. Journal of Membrane Science, 415-416, 1-8.

16. Steinhauser G. 2008. Cleaner production in the Solvay Process: general strategies and recent developments. Journal of Cleaner Production, 16, 833-841.

17. Tran N., Drogui P., Blais J., Mercier G. 2012. Phosphorus removal from spiked municipal wastewater using either electrochemical coagulation or chemical coagulation as tertiary treatment. Separation and Purification Technology, 95, 16-25.

18. Zamparas M., Gianni A., Stathi P., Deligiannakis Y., Zacharias I. 2012. Removal of phosphate from natural waters using innovative modified bentonites. Applied Clay Science, 62-63, 101-106. 